NOTICE: this is the author's version of a work that was accepted for publication in Topics in Early Childhood Special Education Journal. Changes resulting from the publishing process, such as peerreview, editing, corrections, structural formatting, and other quality control mechanisms may not be reflected in this document. Changes may have been made to this work since it was submitted for publication. A definitive version was subsequently published as: Boavida, T., Aguiar, C., \& McWilliam, R. A. (2014). A training program to improve IEP/IFSP goals and objectives through RBI. Topics of Early Childhood Special Education, 33(4), 200-211. doi: 10.1177/0271121413494416

\title{
A Training Program to Improve IFSP/IEP Goals and Objectives through the Routines-
}

\section{Based Interview}

Tânia Boavida

ISPA - Instituto Universitário de Ciências Psicológicas, Sociais e da Vida, Portugal

Rua Jardim do Tabaco, 34/ 1149-041 Lisboa

tboavida@ispa.pt

Cecília Aguiar

ISCTE - Instituto Universitário de Lisboa

Av $v^{\mathrm{a}}$ das Forças Armadas, 1649-026 Lisboa, Portugal

cecilia.rosario.aguiar@iscte.pt

R. A. McWilliam

Siskin Children's Institute

1101 Carter Street, Chattanooga, TN 37402, USA

Robin.Mcwilliam@siskin.org 
A Training Program on IEP/IFSP' Objectives Quality, 2

Author Note

This work was supported by the Fundação para a Ciência e a Tecnologia [grant number SFRH/BD/44286/2008].

Address correspondence to tboavida@ispa.pt. 
A Training Program on IEP/IFSP' Objectives Quality, 3

\section{Abstract}

The authors describe a training program designed to improve the knowledge and skills of early childhood interventionists. Within the context of using the Routines-Based Early Intervention approach, this training focused on improving the quality of goals and objectives on individualized plans, through the Routines-Based Interview. We structured the training around five face-to-face sessions and a follow up 3 months later. Here, we describe the development of the program, its content and methods, and the results on improvement of the goals and objectives with 80 professionals. These participants had completed the training, provided pre-training data, and provided post-training data. Results showed that the training described here had the desired very large effect: Quality ratings of goals and objectives increased by over three standard deviations. 


\section{A Training Program to Improve IFSP/IEP Goals and Objectives Through the}

\section{Routines-Based Interview}

Practices often do not match philosophies about family centeredness and functionality in early childhood intervention (ECI; Campbell \& Halbert, 2002). Certain professional activities can, however, bring those philosophies to life. We propose a training program as a promising solution for bridging the gap between philosophy and practice.

ECI has come to be defined as a family-centered endeavor, which means practitioners are expected to interact with families in a friendly and supportive manner, are expected to give families opportunities to make meaningful decisions about how ECI helps them, and are expected to address family-level needs (McWilliam, 2010a). Consistent with this approach has been an understanding that children learn in the contexts that their families and other caregivers, such as teachers, provide (Dunst, Bruder, Trivette, \& Hamby, 2006). Along with this routines-based approach to conceptualizing ECI (McWilliam, 2010b), theorists have pointed out that functional child skills are those that help the child participate in everyday activities, those that promote a normalization of child and family life, and those that capitalize on the many learning opportunities afforded by home and group-care routines (Dunst, Hamby, Trivette, Raab, \& Bruder, 2000). The training program described here was aimed at promoting these concepts of family centeredness and functionality among early childhood interventionists in the Lisbon area. The Portuguese context is briefly described below, but the utility of this training is probably universal. For example, even though much of the supporting research was conducted in the U.S., European notions and policies about the importance of function and participation are quite sophisticated.

\section{IEP and IFSP in Portugal}

In Portugal, young children with disabilities may receive either early childhood special education (ECSE) or ECI services, depending on their age, type of child care 
arrangement, and region of the country they live in (as different regions are distributing resources differently). Therefore, services and supports these children receive can be guided by an Individualized Education Program (IEP, under the Decree-Law No. 3/2008), by an Individualized Family Service Plan (IFSP, known as an Early Intervention Individualized Plan under the Portuguese Decree-Law No. 281/2009), or by both. If a child has both plans, “the IFSP should dovetail with IEP” (Decree-Law No. 281/2009, p. 7300). Although different, both documents require active participation of the family and the use of the International Classification of Functioning, Disability, and Health (ICF; World Health Organization, 2001) as the method for documenting children's functioning and the environmental facilitators and barriers to social and educational participation. These requirements, although consistent with the Key Principles of ECI (Workgroup on Principles and Practices in Natural Environments, 2007), and addressing major challenges such as individualization and parent involvement (Drasgow, Yell, \& Robinson, 2001; Jung \& McWilliam, 2005), do not seem to be reflected in IFSPs or IEPs (Simeonsson \& Ferreira, 2010).

\section{Research on Actual Practices in ECI}

In a literature meta-analysis on family-centered practices, Dunst, Trivette, and Hamby (2007) concluded that the effect of professional practices on intervention outcomes is mediated by self-efficacy beliefs, so practices should incorporate opportunities for families to make choices and respect for families' decision making. However, available studies on family involvement and participation in ECSE and ECI in Portugal (e.g., Almeida, 2009; Figueiredo, Aguiar, \& Pimentel, 2013; Pereira, 2009; Pimentel, 2005), suggest limitations exist in the implementation of family-centered practices: Parents are still not equal partners in decision-making regarding assessment, planning, and implementation of interventions. This 
attenuated involvement of families might then have an impact on the goals and objectives on IFSPs/IEPs.

Research on IFSP/IEP goals and objectives in Portugal has shown an excess of goals and objectives per IEP/IFSP. Boavida, Aguiar, McWilliam, and Pimentel (2010) found a mean of 38.18 goals per IEP, ranging from 4 to 95 . Furthermore, Portuguese plans have lacked specificity in the writing of goals and objectives (i.e., did not address observable or measurable behaviors) and inadequately contextualized skills within natural routines and settings (Boavida et al., 2010; Campelo \& Nunes, 2008; Valentim, 2006). These results are consistent with previous research on American IEP and IFSP goals (Goodman \& Bond, 1993; Grisham-Brown \& Hemmeter, 1998; Jung \& McWilliam, 2005; Pretti-Frontczak \& Bricker, 2000; Yell \& Stecker, 2003) and support the need for strategies to bridge the gap between recommended and actual practice. Thus, interventions aiming to support ECI and ECSE professionals in the development of family-centered, meaningful, measurable, and functional goals are of critical importance (Boavida et al., 2010). Because the low quality of Portuguese IEP goals and objectives might be associated with a lack of full understanding of familycentered practices, training should focus on practices consistent with a family-centered conceptual framework for developing the IFSP or IEP (Jung \& McWilliam, 2005).

One family-centered framework is the five-component model for ECI in natural environments, also called Routines-Based Early Intervention (RBEI, McWilliam, 2010a), which includes the Routines-Based Interview (RBI, McWilliam, 2005; McWilliam, 2010a). A preliminary study (McWilliam, Casey, \& Sims, 2009) showed that, compared to the traditional approach of developing the IEP, the RBI generated more functional goals.

\section{A Training Program to Improve the Quality of Goals and Objectives}

The purpose of this training was to improve the knowledge and skills of early childhood interventionists, with a particular focus on improving the quality of the goals and 
objectives (including reducing the number) on the plans. We considered high-quality goals to meet certain criteria: (a) be appropriate for the context, supporting natural caregivers' and families' routines and reflecting real-live situations; (b) reflect family priorities; (c) address meaningful skills necessary or useful for the child's participation in family, classroom, and community routines; (d) be free of jargon; (e) be specific and measurable, with meaningful criteria for generalization and timeliness (Bailey et al., 1998; Jung \& McWilliam, 2005; McWilliam, 2010a; McWilliam et al., 1998). Specifically, participants were trained to use the RBI (described later), which is designed to help families identify their own priorities for child and family goals. The contextual basis of this needs assessment encourages families to think about the details of their everyday lives, thus promoting their ability to specify what they want to change. The need for this training in Portugal was evident from aforementioned existing data about the low quality of Portuguese IEP/IFSP goals and objectives (Boavida et al., 2010; Campelo \& Nunes, 2008; Valentim, 2006). In the following sections, the rationale for in-service training is presented, along with a description of how the program was developed and a description of the final version of the program.

In-service training. Supporting ECI and ECSE professionals in the development of high-quality goals and objectives through in-service training requires effective methods and strategies for adult learning. Bransford et al. (2000) highlighted three key principles related to successful adult learning:

1. Students' initial preconceptions and understanding must be taken into consideration when presenting new concepts and information.

2. Students, in order to develop competence, ought to have solid factual knowledge, understand it in the context of a conceptual framework, and organize it so it can be easily retrieved and used. 
3. Learners must take control of the learning process by defining their learning goals and monitoring their own progress.

Building on the work of Bransford and colleagues (2000), Trivette, Dunst, Hamby, and O'Herin (2009) conducted a research synthesis on the characteristics of adult-learning methods and strategies and their consequences on learners' knowledge, skills, attitudes, and self-efficacy beliefs. Results showed that learning methods and practices more actively involving learners in the acquisition, use, and evaluation of the new knowledge and practice had the most positive goals and objectives. According to the authors, training opportunities should include multiple learning experiences, high rates of learners' self-assessment of their experiences, instructor-facilitated learner assessment, and a small number of learners $(<30)$ and should last more than 10 hours across multiple occasions. These recommendations were the starting point for the training described in the present paper. As specified later in this article, the training consisted of 22 classroom hours, across five sessions (four sessions of 4.5 hours and one of 4 hours), and an optional final session. The trainer worked with multidisciplinary teams of 10-20 participants.

Development of the training program. To develop the program, we pilot tested a preliminary version. We hypothesized that this training would result in teachers' developing fewer and more functional IFSP/IEP goals and objectives.

The pilot study is described briefly. Details about the content of training are provided in the Final Version of Training: Training Content and Method Delivered section below, and the evaluation of that final training program is presented after that.

Participants. Eighteen teachers, together with other ECI professionals, participated in four training groups (see the Final Version of Training: Training Content and Method section for more detail) in four different regions of Portugal. Before the passage of the new DecreeLaw No. 3/2008 and Decree-Law No. 281/2009, ECSE or ECI teachers were the main 
professionals responsible for developing EIP. Therefore, we asked each teacher to supply one EIP or IFSP developed before the training and one developed after the training.

The mean age of the teachers was 42 years $(S D=5.15)$, and they had 17.12 years of education $(S D=1.41), 17.47$ years of experience as educators $(S D=5.41), 2$ years of experience in special education $(S D=5.59)$, and 4.12 years of experience in early childhood intervention $(S D=2.09)$.

Method. Because few changes needed to be made to the training program, the description of the training is provided in the Final Version of Training: Training Content and Method section below. In brief, it consisted of four sessions of 4-4.5 hours on (a) key concepts, (b) ecomap and RBI (two sessions), (c) functional-goal writing, and (d) other RBEI components (i.e., primary service provider, support-based home visits, collaborative consultation to child care). The evaluation of the pilot training was based on the number and quality of IEP goals, as measured by the Goal Functionality Scale III (GFS III; McWilliam, 2009). Designed to evaluate the quality of IEP/IFSP goals/objectives, it consisted of seven items: (a) indication of participation in routines (engagement), (b) specificity of the desired behavior, (c) necessity of the skill, (d) quantification of the acquisition criterion, (e) relevance of the acquisition criterion, (f) relevance of the generalization criterion, and (g) relevance of the timeframe criterion. Each goal/objective was rated independently on a scale of 1-4: not at all, somewhat, much, or very much. In this pilot study, because Cronbach's alpha coefficient for all 7 items was $.92(N=18)$, a single composite measure - the GFS III overall mean score - computed as the mean of scores across all goals, was used. For each goal, we computed the sum of scores (i.e., highest score possible $=28$ ) and, for each IEP/IFSP, the mean of scores across all goals, so the higher the score for a goal/objective the higher the quality and functionality. 
GFS III ratings of IEP/IFSP goals were made by two researchers, one of whom rated all the IEPs/IFSPs, and the other rated $20 \%$ of the IEPs/IFSPs. Interrater agreement was $83.38 \%$, with a weighted kappa of .62, and an intraclass correlation of .72 .

Findings. This pilot study showed that, after the training, the EIP/ IFSP developed contained fewer and more functional goals and objectives. As a result of participants' conducting the RBI and then writing goals, they developed an average of 9.28 goals per IEP $(S D=4.32)$, compared to the pretraining average of 38.33 goals per IEP $(S D=24.31)$. The effect size was very large $(d=2.03)$. The goals and objectives written after the training were more functional, with a mean goal functionality score of $14.08(S D=3.68)$ out of a possible score of 28 , than those written before the training $(M=7.79, S D=.63)$. Again, the effect size was very large $(d=2.92)$.

Changes resulting from pilot study. The pilot study informed us that the training had potential that would be enhanced with some minor changes. First, assessment of children in ECI in Portugal must now include the development of a functionality profile with reference to the International Classification of Functionality - Children and Youth (ICF-CY, WHO, 2007) (see Functionality profile - International Classification of Functioning, Disability and Health section for more detail), but trainees did not obtain enough detailed information from the RBI to complete valid functionality profiles. The question of validity arose from the high variability in ICF-CY codes. In the pilot study training, the Measure of Engagement, Independence, and Social Relationships (MEISR, McWilliam \& Hornstein, 2007) (see MEISR section for more detail) was not overtly linked to the ICF-CY, so one change to be made was explicit linking of these two tools (Boavida, Ornelas, Aguiar, \& McWilliam, 2013). Second, it appeared that trainees did not understand the purpose of the functional goals they were taught to develop. Explaining how the goals were central to effective service delivery through implementation of the RBEI model was important to include in the training. 
Third, although functional goals were the outcome aimed for, this outcome was expected to vary according to the fidelity with which the RBI was carried out. Furthermore, the RBI was the specific process used to determine what the functional goals were, which is more important than how they are written. Requiring participants to submit a video recording of their conducting an RBI was therefore added to the training program. This video was to be scored with the RBI Implementation Checklist (McWilliam, 2010b) and feedback was to be provided to the trainee. Once these three additions to the training program were planned, the actual training was ready to occur.

\section{Final Version of Training: Training Content and Method Delivered}

The training program was built around five face-to-face sessions and a sixth contact by e-mail. Table 1 shows the duration, main content, and main method for each of the sessions. This section describes the content of the training and the training methods used for each session. -Insert Table 1

Session 1: ECI concept and philosophy. The training began with an explanation of the purpose of the training, introductions, and an overview of the content.

The training on IEP and IFSP - Development of quality goals and objectives started with a brief presentation of the recent Portuguese research indicating the need that led to the design of this training. To help in the contextualization, the trainer's background and motivations were also briefly presented and discussed.

The next step was to explore the group characteristics and functioning (e.g., if they already work together) by inviting the trainees to introduce themselves. They were asked to talk about their background, the needs they experience in their daily practice, the motivation that brought them to the training, and their expectations. 
Once the trainer had a perspective of the group's background, motivation, and expectations, a more directed introduction to the content, goals, and methods was possible. To promote full participation and ensure that participants got the most out of the training, it was essential that they were aware of the content and goals of the training as well as of the expectations for them. At the beginning of each session, specific goals and content were outlined.

Concept and philosophy of ECI. It was deemed important to arrive at a common understanding of the concept and philosophy of ECI. Participants were mainly ECI professionals, Special Education teachers and regular classroom teachers and they had different levels of knowledge and experience in the field, such as in their initial academic training, the number of years of experience in ECI, and the programs in which they had worked. The first day, therefore, was devoted to the search for this common understanding through activities promoting (a) the exchange of knowledge and perceptions and (b) teamwork. Brainstorming and the case method of instruction were the two primary activities. Brainstorming concept of ECI. Brainstorming is a well-known and often-used group procedure in the generation of creative ideas (Osborn, 1961). As a powerful group procedure, when properly applied, the potential of brainstorming goes beyond the fluency and quality of ideas generated (Isaksen \& Gaulin, 2005): It improves teamwork because it is a sharing activity that encourages participation in a safe climate with divergent thinking.

After an explanation of the brainstorming rules, a slide with the words "early intervention" was displayed and the participants were invited to give short definitions of the term as well as key concepts that go along with it. They were also invited to write all the ideas that crossed their minds if they did not have the chance to say them at that moment, so they did not forget them, and could share them as soon as possible. 
During the brainstorming, the trainer acted as a facilitator, writing down, rapidly, all the ideas on a flipchart or board. The trainer's role was crucial to the success of the session (Isaksen \& Gaulin, 2005), and as important as recording the ideas was guiding the group's interaction, by reinforcing the guidelines and encouraging all members to participate.

Once all participants' contributions were recorded and no one had anything to add (about $10 \mathrm{~min}$. ), the information on the flipchart was discussed and combined in light of the legal framework and recommended practices. For this discussion, besides the information in the flipchart, slides with excerpts from the Portuguese law and from Dunst (2007) and Bruder (2010) were used.

This was an adaptation of the traditional use of brainstorming, because it was not focused on creative-idea generation, the session was shorter than the 30-45 minutes recommended by Osborn (1963, cited by Isaksen \& Gaulin, 2005), and the follow-through was conducted right after the brainstorming. However, we think that this adaptation was the best way to achieve our aims. Being the first activity of the training after the presentation, it could provide the model of the participation style expected from the group. Our aim was to take advantage of contributions from all of the members because of what their different backgrounds could offer, in a judgment-free environment. This exercise was designed to help participants understand that their contributions were important to the training.

After the brainstorming, through the discussion of the different contributions, framing them within the latest legislation and research, we expected to reach a common vision of ECI. Nevertheless, a deep understanding of the concepts was not considered possible without understanding the philosophy supporting them.

Case method of instruction: Philosophy of ECI. The case method of instruction (CMI) was the principal method used for teaching about the ECI philosophy underlying RBEI model (e.g., functionality, family centeredness, teaming). CMI is an instructional procedure for 
teaching general skills of decision-making, using real life situations, and requiring the active participation of trainees in the learning process (McWilliam, P.J. \& North Carolina University, 1996). It was initially developed for ECI by P. J. McWilliam (1992) and since then it has been used with promising results in the instruction of family-centered service provision and teaming (Snyder \& McWilliam, 1999).

The CMI in ECI personnel preparation has distinctive characteristics (Snyder \& McWilliam, 2003). The cases are written stories that describe realistic everyday issues encountered by ECI professionals in their work. These stories, though realistic, are not extreme and are open-ended and dilemma-based. They are unsolved, so trainees can discuss, with the trainer, potential solutions to the dilemma. The focus is on decision making, not on a right answer.

The decision to use a case story in this training was made after the pilot training revealed the need to deepen the ECI philosophy in a way that trainees could actively build on their knowledge and experiences. A story was written so that topics such as family centeredness, natural environments, inclusion, transdisciplinary services delivery, and legal issues would be addressed, bridging the gap between theory and practice. Moreover, the details of the Portuguese everyday context and dilemmas found by ECI professionals were considered.

A list of case discussion questions was designed to guide the debate. The first two sets of questions are related to legal requirements, knowledge of the law regarding ECI and the EIP and IFSP, and the ICF-CY. The next two sets of questions were related to the identification and analysis of particulars of the case. The last two sets of questions were related to what actions might be taken and their consequences.

After the follow-through of the brainstorming, a brief overview of CMI was presented, along with the purpose of its use in this particular training and of what was 
expected from the trainees during the case discussion. A copy of the case story and discussion questions was distributed to each trainee. Ten minutes after a first read-through, participants were grouped in small groups of four or five.

Groups were designed to be as heterogeneous as possible, regarding professionals' basic training and experience, so they could support each other and provide different contributions to the case preparation. They had 45 minutes to prepare the case discussion. During this time, the trainer was in the room and joined the groups, whenever requested, to answer any questions.

Once all the groups finished the preparation, the whole-group discussion took place. The discussion followed the questions provided by the trainer. Each group gave an initial answer and then anyone could intervene with new ideas, combination of ideas, or any contribution. For the first four sets of questions, slides with information and theory about the specific themes were introduced.

Once again, the trainer acted as a facilitator, writing down all the ideas on a flipchart or board. The trainer was also responsible for an atmosphere of suspended judgment, promoting the use of critical thinking skills and keeping the discussion going.

The main purpose of using CMI in this training was the consolidation of the ECI philosophy. Through the challenges of recommended practices and barriers to their implementation found in day-to-day work with families and their children, trainees were invited to find solutions to solve the presented dilemma based on their knowledge and experience.

Because trainees did not possess the same knowledge regarding ECI, one initial aim was that through small groups' discussion, the main issues were addressed and everyone had the opportunity to contribute with their knowledge and see their questions addressed. 
The process above described also allowed for a successful collaborative problemsolving experience. As Snyder and McWilliam (2003) clarify, trainees “apply knowledge, hear alternative view points, reflect on their beliefs and values, and use a decision-making process to solve dilemmas" (p. 286). This experience can increase consciousness of the benefits of working in a transdisciplinary team in the pursuit and achievement of better solutions.

Routines-Based Early Intervention. After the discussion of the ECI concept and philosophy, through brainstorming and the CMI, the RBEI model was presented as a useful bridge between philosophy and practice.

The RBEI model is based on five components. Each component is comprised of a principle of service provision accompanied by a major practice: (1) understanding the family ecology through the development of an ecomap; (2) assessing needs and developing a functional, family-centered intervention plan by conducting a Routines-Based Interview (RBI) and following the seven steps of functional goal writing; (3) organizing integrated services through the use of a primary-service-provider approach; (4) conducting supportbased, consultative home visits; and (5) consulting collaboratively in child care through integrated therapy.

Although each of these components can be used separately, they are enhanced when used together. Because of the specific goals of the training and time management issues, this training focused on the first two elements.

Session 2: Ecomap and the RBI. An ecomap is a drawing of the family and their perceived supports. By developing it, professionals get to know the family ecology. Completing an ecomap in the early stages of contact with the family is useful for (a) showing interest in the whole family, rather than just the child and (b) developing a friendly and interested relationship with the family. Moreover, an ecomap gathers much information in a 
short amount of time, showing the people and agencies that provide formal and informal support, as well as the strength of the support or stress provided by each source of support (McWilliam, 2010a). Understanding the family and child ecology is a foundation for conducting the RBI and designing interventions that are relevant and meaningful to the family.

The RBI is a semi-structured interview designed to create a positive relationship with the family, assess family and child functioning, and develop a list of functional goals. The interviewer asks about daily routines, from the beginning to the end of a typical day. Within each routine, follow-up focus on what the whole family does, what the child engagement, social relationships, and independence are like, and how satisfied the family is with the routine. These questions require the interviewer to know about child development and family functioning and to have "good people skills". A well-conducted RBI will assess the goodness of fit between the child and the demands of the routine (McWilliam, 2010a; McWilliam et al., 2009).

Example video. The second day of training was devoted to the analysis of a videorecorded example of an ecomap and an RBI. The video display occurred at two separate times, first while explaining the development of the ecomap and the second while explaining the RBI.

Before the ecomap video was shown, a presentation about the need to develop the ecomap and the steps for conducting an ecomap were discussed. Trainees were asked to draw an ecomap as the parent on the video discussed her formal and informal supports. The video was stopped to highlight main points or when participants wanted clarification or discussion. Additional discussion occurred at the end of the video.

Before the RBI video display, a presentation about the need to carry out a routinesbased assessment and the steps of this assessment were conducted. The trainees were 
informed about what was expected of them during the demonstration. Each participant received an RBI Implementation Checklist (McWilliam, 2010b). As before, the video was stopped to highlight main points and to engage in discussion. After the video demonstration, relevant theory and information about critical interview behaviors were presented. Through the video demonstration, along with discussion, the trainees were expected to integrate new information and concepts.

Session 3: RBI skills practice. In the third session, trainees practiced RBI skills in a simulation exercise. Role-play is an active learning technique that allows the practice of a set of behaviors and skills required to carry out specific practices. van Ments (1999) distinguished between two major kinds of role-play: one dealing with the practice of skills and techniques and the other with the exploration of behaviors, feelings, and attitudes. The role-play used in this training was intended to take advantage of both kinds.

Three different vignettes, each describing an ECI case through the perspective of a mother, and the perspective of a regular teacher, based in the Portuguese context, were created. The participants were asked to organize themselves into groups of four or five and to decide on the role of each person: parent, regular teacher, interviewer, and one or two observers. Once the roles were assigned, each group received a vignette. The "parents" and "teachers" were instructed to read their roles and to prepare to make up details; they were also asked not to make the interviewers' role excessively difficult. The "interviewers" and “observers" received an RBI Implementation Checklist (McWilliam, 2010a, 2010b) and were both asked to read it. Whereas the interviewers used it mainly to prepare themselves, the observers used it to give feedback on the interviewers' performance.

Participants had 5 minutes to prepare themselves and were instructed to role-play an RBI, starting with an ecomap and concluding with the selection of goals by the family. The entire interview was planned to last 90 minutes. All groups role-played at the same time. 
During the role-play the trainer rotated among the groups to clarify remaining questions and, whenever appropriate, step in and model a specific role (generally as interviewer). Another function of the trainer was to keep track of the time, informing the trainees on which part of the interview they should be at particular times.

Debriefing is important in role-play. In this training, the first debriefing step was at the small-group level, when participants discussed their feelings and thoughts while playing their roles, including giving and receiving feedback from the observer(s). The second step was in the whole-group discussion.

Trainees were invited to talk about how they felt while playing different roles, and the trainer responded by exploring reasons for certain responses. The trainer also discussed interviewing skills observed, along with hints for improvement. By the end of the debriefing, the trainer made sure all remaining concerns about how the role-play went were addressed.

After the first role-play, trainees were asked to conduct a different role-play, changing vignettes and roles. This second role-play followed the same procedures as the first but lasted for about half the time because and trainees, from time to time, were asked to jump further in the interview.

The main purpose for this role-play was to practice conducting an RBI in a safe and controlled environment. Interviewers received feedback related to the extent to which they followed the RBI structure. They also had an opportunity to discuss how they felt conducting the interview. They received feedback from the observer(s) and from the "parent" and "teacher" about how at ease and comfortable these players felt. Finally, in the whole-group debriefing, they had the opportunity to hear about each others' experience and to consider and reflect on alternative viewpoints and on their own personal competence and values.

Session 4: Functionality. The whole training is a process for arriving at the heart of one issue: functionality. Most preservice training about assessment and intervention is 
organized according to traditional developmental domains such as motor, cognitive, communication, adaptive, and social development, focusing on identifying and correcting deficits. The functional approach proposed by RBEI focuses on the skills needed in the home, community, and classroom, to promote child and family success in these environments. It is therefore associated with the functional domains of engagement, independence, and social relationships (McWilliam, 2010a).

Portuguese law requires child and family assessment to be documented with the use of ICF (see Table 1) so a profile of functionality can be identified. Hence, we provided trainees with information on the ICF, along with examples of how to use the RBI to contribute to the development of a meaningful ICF profile.

\section{Functionality profile: International Classification of Functioning, Disability and}

Health. Developed by the World Health Organization (WHO, 2001), the ICF belongs to the family of international classifications of individuals' health. As defined by WHO (1946), "health is a state of complete physical, mental and social well-being and not merely the absence of disease or infirmity."

The ICF is based on a dynamic model of functioning that reflects the ongoing influence of the environment on the person. Thereby, it is a multidimensional classification consisting of four interrelated components: body functions, body structures, activities, and participation (WHO, 2001). For children and youth, in part because of their rapid development, people familiar with the ICF saw the need to develop ICF-CY (WHO, 2007), which expands ICF coverage by providing specific content and additional details across the developmental stages (WHO, 2007).

Children's development depends on continuous interactions with the family and other caregivers. Despite the fact that functioning should be assessed in the context of the family system, Portuguese teachers have been found to develop functionality profiles assuming a 
linear relationship between participation restrictions and disability, making little reference to functional content or the environment (Ferreira et al., 2012).

Professionals might persist with this diagnosis-driven approach to assessment because it is difficult to shift to a functional way of thinking. One tool that combines a developmental, a functional, a family-centered, and an ecological perspective in assessment is the MEISR (McWilliam \& Hornstein, 2007), described in detail in the next session. The MEISR is developmental in that the items are organized according to the ages at which the skills usually begin. It is functional in that the skills are those commonly needed for successful participation in everyday routines. It is family centered in that families (not professionals) score their children's functioning. It is ecological because the profile is organized by everyday routines. After the pilot study, in which the need for addressing problems with completing the profile with reference to ICF-CY were detected, a cross-walk of the MEISR with the ICF-CY was presented in the final version of the training (Boavida et al., 2013).

\section{Measure of Engagement, Independence, and Social Relationships. The MEISR} (McWilliam \& \& Hornstein, 2007) is an instrument designed to develop a profile of functioning of children younger than 5 years old. It is meant to be completed by a caregiver who knows the child in the home or, as we suggest in this training, by the interviewer, after conducting the RBI, based on the information provided by the caregiver. Over 300 items representing functional skills are organized by everyday home routines. Each item is coded according to the corresponding functional area (engagement, independence, or social relationships), developmental domain (cognitive, communication, motor, adaptive, or social), and child outcome (social relationships, taking action to meet needs, or acquiring knowledge and skills). 
Writing a functional profile. The first purpose of this activity was to provide the trainees guidelines for writing the profile, which was new for most of them. Second, we hoped the trainees would see the value of both functionality and teamwork.

After briefly reviewing the ICF-CY and presenting the MEISR, the trainer gave each participant a copy of notes taken during the video-recorded RBI participants watched in the second session. In groups of four-five participants, they were given 50 minutes to complete the following four steps for writing the child functionality profile:

1. List RBI information regarding child functionality and context;

2. Complete the MEISR with the information listed in the previous step;

3. Assign the relevant qualifier for each ICF-CY code checked in MEISR, and considering the expected typical development for a child of the same age,

4. Write a short profile describing the child's significant characteristics for the context and indicating, for each characteristic, the ICF-CY category and qualifier in brackets.

After trainees wrote their profiles, a whole-group discussion took place. First, the different profiles are presented, compared, and discussed. Finally, trainees were invited to reflect and compare this method for writing profiles with the way they had been writing profiles.

Writing functional goals and objectives. We developed this training with a particular outcome in mind: that trainees would be able to write functional goals and objectives. Goals and objectives are only as functional as the assessment that produced them (McWilliam, 2010a). One can write an existing goal/objective coming from a standardized test and end up with a well-written nonfunctional goal/objective. The RBI produces goals and objectives the family has chosen as well as the necessary information for writing them in a functional way. 
A copy of "steps to build a functional goal/objective" was supplied to trainees along with a succinct introduction. Next, the whole group wrote the first child goal chosen by the family in the video demonstration of the RBI. They also wrote the first family-level goal.

Once there were no further questions, small groups were formed, and each group wrote two child-level goals and one family-level goal from the RBI video. All the written goals were discussed by the whole-group. Trainees were encouraged to practice the exercise with goals not discussed at the session and to take questions to the next session.

Session 5: Functional goals, other RBEI components, and follow up. This session began with the presentation and discussion of the goals written by the trainees at home during the week. Once all the questions were addressed a summary of the training took place.

Other RBEI components. As we stated before, the different RBEI components can be used separately but their efficacy is enhanced when there are used together. So, we could not finish the training without an overview of how what the trainees have learned could be used in the big picture, namely with the other RBEI components: (1) Transdisciplinary Service Delivery, (2) Support-Based Home Visits, and (3) Collaborative Consultation to Child Care.

Follow up. Feedback about skills' implementation in practice contexts and follow-up coaching are efficacious components of in-service training (Snyder, Hemmeter, \& McLaughlin, 2011). Accordingly, these components are an integrated part of this training program.

The last part of the fifth day of training was devoted to the preparation of the followup. The proposed field work was presented and, in small groups, trainees discussed barriers, and respective solutions, to its realization. Finally, information on the e-learning platform that was to be used for follow up purposes, the way to access it, and how to use it was presented and discussed. 
During the succeeding 3 months, trainees are expected to conduct a RBI and write the functional goals and objectives in practice contexts. During the first 3 weeks, a question is placed weekly at the platform, addressed to all the trainees, and the answers, questions, or comments are open to discussion. After these 3 weeks, each trainee was to send a video recorded RBI and post the RBI functional goals through the platform, receiving written feedback both on the RBI and on the goals writing.

Session 6: Final feedback. In addition to the individual written feedback, an optional final 3-hour session was held. In addition to providing live feedback, including suggestions for improving the training, trainees could have any remaining questions answered.

\section{Evaluation}

\section{Participants}

The 35 Local Intervention Teams working in the Lisbon and Tagus Valley area were invited, through the region Subcommittee of the Portuguese National System of Early Childhood Intervention (created with Decree-Law No. 281/2009), to participate in this training. Along with the team members the invitation was extended to other professionals working directly or indirectly with the teams. The training was conducted with the first 14 groups of professionals (working in Local Intervention Teams, in private nonprofit institutions for child care and preschool, school groups, and other community services), that contacted us showing their interest. This training was offered to participants free of charge and was certified by the Científico-Pedagógico da Formação (i.e., the Scientific-Pedagogical Council for Continuous Training) awarding one credit to each participating teacher.

From the 284 professionals that attended the training 201 completed it and we have collected 183 IEP/IFSP prior to the training and 109 after the training.

Current findings report to the participants in this training that, (1) completed the training, (2) provided pre-training data, and (3) provided post-training data. Eighty 
professionals met these requirements (Boavida, Aguiar, \& McWilliam, 2012). Thus, these 80 professionals each supplied one EIP or IFSP developed before the training and one developed after the training. Of these 80 professionals, $81 \%$ attended all the training sessions, $15 \%$ missed one training session, and less than $4 \%$ missed two training sessions. Participants were mainly teachers (21 ECI teachers, 17 Special Education teachers, and 23 regular classroom teachers), but 8 were therapists, 5 were psychologists, and 4 were social workers. Thirty-eight of them worked at a Local Intervention Team, 14 at private nonprofit organizations for child care and preschool, 24 at school groups (a conglomerate of schools across ages), and one at other community service. The professionals' average age was 38.62 years $(S D=8.29)$, they had an average of 17.25 years of education $(S D=1.56)$, and they had an average of 14.01 years of service $(S D=8.41)$.

\section{Method}

To evaluate the quality of IEP/IFSP goals and objectives written by the professionals, we used the Goal Functionality Scale III (GFS III; McWilliam, 2009). Designed to evaluate the quality of IEP/IFSP goals and objectives, the GFS III consisted of seven items rated on a scale of 1-4 (as described in the pilot study section earlier in this article). As Cronbach's alpha coefficient for all 7 items was .92, a single composite measure - the GFS III overall mean score - computed as the mean of scores across all goals, was used. The mean was necessary because each plan could have a different number of goals. For each goal, we computed the sum of scores, so the higher the score for a goal/objective the higher the quality. The highest possible score was 28 , and the lowest possible score was 7 .

Goals with very low scores were not written as actual goals but as (a) announcements of development areas to be addressed (e.g., To develop gross motor skills), (b) strategies (e.g., Highlight and enhance attitudes of fulfillment of tasks), or (c) otherwise missed all 7 items (e.g., José will observe other children playing, at the park and at school, with physical 
or verbal prompt from the adult. We will know he can do this when he performs this activity only with verbal or physical prompt from the adult). Examples of objectives with the highest scores are (1) José will participate in diaper changing and dressing times, at home and day care, by raising his legs or giving the asked body part (hand, arm, foot, leg). We will know he can do this when he raises or gives the requested body part, when asked, 4 times a day at any of the described times, at home and at child care in 3 weeks; (2) Maria will participate in meals, by eating the second dish with a spoon by herself. We will know she can do this when she eats by herself, with a spoon, half of the second dish, at one of the principal meals (lunch or dinner) of the day in 2 weeks.

Two researchers scored the GFS III, one rating all the IEPs, and the other independently rating $33 \%$ of them. The obtained interrater exact agreement was $79.75 \%$, with a weighted kappa of .59, and an intraclass correlation coefficient of .70.

\section{Findings}

This evaluation showed that, after the training, the EIP/ IFSP developed contained fewer goals/objectives and more functional ones. Before the training, plans had an average of 23.86 child level goals/objectives $(S D=35.86)$. After training, the number plummeted to an average of 5.22 child level goals/objectives per plan $(S D=2.24 ; t(79)=4.78, p<.001, d=$ 0.99). Before training, the average GFS III score per plan was $8.94(S D=3.03)$. After training, the score rose to $19.77(S D=4.09 ; t(67)=-16.09, p<.001, d=3.04)$, as shown in Figure 1. Both changes represent a large effect size.

-Insert Figure 1

\section{Discussion}

The training described here had the desired effect: Goals and objectives improved. The excessive number of them, per plan, came down to a reasonable size, and the quality 
ratings went up, by over three standard deviations. This training has three kinds of implications for ECI practice.

\section{Implications of Improving Goals and Objectives}

First, the implications of improving goals/objectives are that the actual support early childhood interventionists provide could be improved. This link between goals and support would only be true if professionals actually follow the plan. One needed area of research is about the extent to which goals are actually addressed and whether that association is mediated by the functionality of the goals. In other words, if goals are less functional, do early childhood interventionists address them less than if they were more functional? Does functionality make any difference at all to whether goals are addressed? Accountability systems are not tied to children's performance on goals, which has its advantages and disadvantages. The advantage of not taking children's goal attainment seriously is that the criteria set for goals are imprecise and professionals could attenuate them so they, the professionals, would look more successful. The disadvantage of not including goal attainment in accountability systems is that it diminishes the incentive to establish high-quality goals and to address them. In the U.S., for example, the federal government holds states accountable for child progress on ratings of three supposedly functional child goals and objectives, not on goal attainment.

\section{Implications of Training Personnel to Interview Families}

When early childhood interventionists are trained to interview families about the details of their daily lives, three things can happen. First, families by and large like having someone knowledgeable show interest in the details of their parenting. Families might be anxious, especially at entry to the program, and eager to have someone hear about what's going on in the home. The RBI is considered a fast way of developing a positive relationship with the family (McWilliam, 2010a). Second, in the course of talking about their daily lives, 
families disclose much information about their family life, beyond simply what the child does. The interviewer does not have to be intrusive for families to end up talking about family-level issues. Third, early childhood interventionists have the opportunity to become conscious of the effects of the environment on child and family functioning. As they hear families talk about how the social (e.g., other family members, family rituals) and physical ecologies (e.g., furnishings, toys, spaces) affect and are affected by the families' interests and abilities, they learn about the bioecological nature of development (Bronfenbrenner, 1986).

\section{Implications of Organizing Intervention by Routines}

How a child experiences breakfast time, hanging-out time with his or her parents, bath time, diaper changes, and so on form that child's curriculum. Caregivers of the child are the child's teachers. These routines or ecocultural niches (Weisner, 2002) are the daily lessons where the teaching occurs. If the child attends a classroom program, such as a nursery or preschool, another whole set of routines and caregivers are added to the home ones. ECI specialists who understand this basis of functioning within routines recognize that cultural forces play themselves out in routines. Differences between families in ethnicity, socioeconomic status, or belief systems about childrearing are manifested in how they do breakfast time, hanging-out time, bath time, diaper changes, and so on. The training described in this paper emphasized routines as the basis for assessment and intervention. Trainees might therefore be expected to be effective in responding to cultural variation, to individual-family variation, and to the goodness of fit between the demands of routines and the abilities and interests of children and their families.

In conclusion, the workshop-based training on the routines-based early intervention model, with a focus on the Routines-Based Interview, can result in goals/objectives of high quality. It can also transform professionals' understanding of how children learn and how ECI works. 
A Training Program on IEP/IFSP' Objectives Quality, 29

\section{References}

Almeida, I. C. (2009). Estudos sobre a intervenção precoce em Portugal: Ideias dos especialistas, dos profissionais e das famílias [Studies of early intervention in Portugal: Ideas of specialists, professionals, and families]. Lisbon, Portugal: Instituto Nacional para a Reabilitação.

Bailey, D. B., Jr., McWilliam, R. A., Darkes, L. A., Hebbler, K., Simeonsson, R. J., Spiker, D., \& Wagner, M. (1998). Family outcomes in early intervention: A framework for program evaluation and efficacy research. Exceptional Children, 64, 313-328.

Boavida, T., Aguiar, C., \& McWilliam, R. A. (2012, October). A training program bridging the gap between philosophy/research and practice in Early Intervention. Paper presented at the DEC's 28th Annual International Conference on Young Children with Special Needs and their Families, Minneapolis, USA.

Boavida, T., Aguiar, C., McWilliam, R. A., \& Pimentel, J. (2010). Quality of Individualized Education Program goals of Portuguese preschoolers with disabilities. Infants and Young Children, 23(3), 233-243.

Boavida, T., Ornelas, M., Aguiar, C., \& McWilliam, R. A. (2013). Linking the MEISR to $I C F-C Y$. Manuscript in preparation.

Bransford, J. D., Brown, A. L., Cocking, R. R., Donovan, M. S. Bransford, J. D., \& Pellegrino, J. W. (Eds.). (2000). How people learn: Brain, mind, experience, and school. Washington, DC: National Academy Press.

Bronfenbrenner, U. (1986). Ecology of the family as a context for human development: Research perspectives. Developmental Psychology, 22, 723-742.

Bruder, M.B. (2010). Early childhood intervention: A promise to children and families for their future. Exceptional Children, 76(3), 339-355. 
Campbell, P. H., \& Halbert, J. (2002). Between research and practice: Provider perspectives on early intervention. Topics in Early Childhood Special Education, 22(4), 211-224.

Campelo, L. F., \& Nunes, C. (2008). A avaliação das práticas centradas na família através dos planos individualizados de apoio à família. International Journal of Developmental and Educational Psychology, XX, 1(3), 55-62.

Decree-Law No. 3/2008 [Decreto-Lei n.॰3/2008 ]. Ministério da Educação. Diário da República, Série n.॰ 4 - 7 de Janeiro de 2008, pp. 154-164.

Decree-Law No. 281/2009 [Decreto-Lei n.॰281/2009]. Diário da República, Série n.॰ 193 - 6 de Outubro de 2009, pp. 7298-7301.

Drasgow, E., Yell, M., \& Robinson, T. R. (2001). Developing legally correct and educationally appropriate IEPs. Remedial and Special Education, 22, 359-373.

Dunst, C. J. (2007). Early intervention for infants and toddlers with developmental disabilities. In S. L. Odom, R. H. Horner, M. Snell, \& J. Black (Eds.), Handbook of developmental disabilities (pp. 161-180). New York, NY: Guilford Press.

Dunst, C. J., Bruder, M. B., Trivette, C. M., \& Hamby, D. W. (2006). Everyday activity settings, natural learning environments, and early intervention practices. Journal of Policy and Practice in Intellectual Disabilities, 3(1), 3-10.

Dunst, C. J., Hamby, D., Trivette, C. M., Raab, M., \& Bruder, M. B. (2000). Everyday family and community life and children's naturally occurring learning opportunities. Journal of Early Intervention, 23, 151-164.

Dunst, C. J., Trivette, C. M., \& Hamby, D. W. (2007). Meta-analysis of family-centered helpgiving practices research. Mental Retardation and Developmental Disabilities Research Reviews, 13, 370-378.

Ferreira, M. S., Simeonsson, R. J., Maia, M. S., Alves, S., Tavares, A., \& Pinheiro, S. (2012). Portugal's special education law: Implementing the International Classification of 
Functioning, Disability and Health in policy and practice. Disability \& Rehabilitation, Ahead of Print: 1-6.

Figueiredo, A., Aguiar, C., \& Pimentel, J. S. (2013). Family involvement in early childhood special education: Perceptions of Portuguese parents and teachers. Manuscript under revision.

Goodman, J., \& Bond, L. (1993). The individualized education program: A retrospective critique. Journal of Special Education, 26, 408-422.

Grisham, J. F., \& Hemmeter, M. L. (1998). Writing IEP goals and objectives: Reflecting an activity-based approach to instruction for young children with disabilities. Young Exceptional Children, 1(3), 2-10.

Isaksen, S. G., \& Gaulin, J. P. (2005). A reexamination of brainstorming research: Implications for research and practice. Gifted Child Quarterly, 49(4), 315-329.

Jung, L. A., \& McWilliam, R. A. (2005). Reliability and validity of scores on the IFSP Rating Scale. Journal of Early Intervention, 27, 125-136.

McWilliam, P. J. (1992). The case method of instruction: Teaching application and problemsolving skills to early interventionists. Journal of Early Intervention, 16, 360-373.

McWilliam, P. J. \& North Carolina Univ., Chapel Hill. Frank Porter Graham Center. (1996). The case method of instruction (CMI) project: Final report [microform] / P. J. McWilliam and Others. Distributed by ERIC Clearinghouse, [Washington, D.C.] : http://www.eric.ed.gov/contentdelivery/servlet/ERICServlet?accno=ED398688

McWilliam, R. A. (2005). Assessing the resource needs of families in the context of early intervention. In M. J. Guralnick (Ed.), A developmental systems approach to early intervention (pp. 215-234). Baltimore, MD: Paul H. Brookes.

McWilliam, R. A. (2009). Goal Functionality Scale III. Chattanooga, TN: TEIDS-Plus Study. Siskin Children's Institute. 
A Training Program on IEP/IFSP' Objectives Quality, 32

McWilliam, R. A. (2010a). Routines-based early intervention: Strategies for supporting young children with disabilities. Baltimore, MD: Brookes Publishing.

McWilliam, R. A. (2010b). RBI implementation checklist. In R. A. McWilliam (Ed.), Working with families of young children with special needs (pp. 44-47). New York, NY: Guilford Press.

McWilliam, R. A., Casey, A. M., \& Sims, J. (2009). The routines-based interview: A method for gathering information and assessing needs. Infants and Young Children, 22(3), 201210.

McWilliam, R. A., Ferguson, A., Harbin, G. L., Porter, P., Munn, D., \& Vandiviere, P. (1998). The family-centeredness of individualized family service plans. Topics in Early Childhood Special Education, 18, 69-82.

McWilliam, R. A., \& Hornstein, S. (2007). Measure of Engagement, Independence, and Social Relationships (MEISR).Nashville: Vanderbilt University.

Osborn, A. F. (1961). Development of creative education. Buffalo, NY: Creative Education Foundation.

Pereira, A. P. (2009). Práticas centradas na família em intervenção precoce: Um estudo nacional sobre práticas profissionais [Early childhood family centered practices: A national study on professional practices]. (Unpublished doctoral dissertation). University of Minho, Portugal.

Pimentel, J. (2005). Intervenção focada na família: Desejo ou realidade [Family-focused intervention: Wish or reality]. Lisbon, Portugal: Secretariado Nacional para a Reabilitação e Integração das Pessoas com Deficiência.

Pretti-Frontczak, K., \& Bricker, D. (2000). Enhancing the quality of individualized education plan (IEP) goals and objectives. Journal of Early Intervention, 23, 92-105. 
A Training Program on IEP/IFSP' Objectives Quality, 33

Simeonsson, R. J., \& Ferreira, M. S. (2010). Projecto da avaliação externa da implementação do Decreto-Lei $n^{\circ}$ 3/2008: Sumário executivo [External assessment of the implementation of Decree-Law No. 3/2008 project: Executive summary]. Retrieved from http://www.dgidc.minedu.pt/educacaoespecial/index.php?s $=$ directorio $\&$ pid $=6$

Snyder, P., Hemmeter, M. L., \& McLaughlin, T. (2011). Professional development in early childhood intervention: Where we stand on the silver anniversary of PL 99-457. Journal of Early Intervention, 33, 357-370.

Snyder, P., \& McWilliam, P. J. (1999). Evaluating the efficacy of case method instruction: Findings from preservice training in family-centered care. Journal of Early Intervention, 22, 114-125.

Snyder, P., \& McWilliam, P. J. (2003). Using case method of instruction effectively in early intervention personnel preparation. Infants and Young Children, 16(4), 284-295.

Trivette, C. M., Dunst, C. J., Hamby, D. W., \& O’Herin, C. E. (2009). Characteristics and consequences of adult learning methods and strategies. Practical Evaluations Reports, 2(1), 1-32. Retrieved from http://www.practicalevaluation.org/reports/CPE_Report_Vol2No1.pdf .

Valentim, J. (2006). Plano individualizado de apoio à família: Um chapéu de chuva ou um conjunto de varas? [Individual Family Service Plan: An umbrella or a set of poles?] (Undergraduate thesis in educational psychology). Lisbon, Portugal: ISPA, IU van Ments, M. (1999). The effective use of role play: Practical techniques for improving learning (2 ${ }^{\text {nd }}$ ed.). London, UK: Kogan Page.

Weisner, T. S. (2002). Ecocultural understanding of children's developmental pathways. Human Development, 45, 275-281. 
A Training Program on IEP/IFSP' Objectives Quality, 34

Workgroup on Principles and Practices in Natural Environments. (2007, November). Mission and principles for providing services in natural environments. OSEP TA Community of Practice-Part C Settings. Retrieved April 5, 2011, from http://www.nectac.org/topics/families/families.asp.

World Health Organization. (1946). Constitution of the World Health Organization. Retrieved from http://apps.who.int/gb/bd/PDF/bd47/EN/constitution-en.pdf

World Health Organization. (2001). International Classification of Functioning, Disability and Health. Geneva, Author.

World Health Organization. (2007). International Classification of Functioning, Disability and Health - Children and Youth. Geneva, Author.

Yell, M. L., \& Stecker, P. M. (2003). Developing legally correct and educational meaningful IEPs using curriculum-based measurement. Assessment for Effective Intervention, 28, 73-88. 
Table 1. Training organization

\begin{tabular}{ccll}
\hline $\begin{array}{c}\text { Session \# and } \\
\text { Duration }\end{array}$ & \multicolumn{1}{c}{ Main Content } & \multicolumn{1}{c}{ Main Method } \\
\hline 1 - & $4.5 \mathrm{~h}$ & $\begin{array}{l}\text { Initial data collection }+ \\
\text { key concepts }\end{array}$ & Case story \\
\hline $2-$ & $4.5 \mathrm{~h}$ & Ecomap + RBI & Video demonstration + discussion \\
\hline $3-$ & $4.5 \mathrm{~h}$ & Ecomap + RBI & Role-play \\
\hline $4-$ & $4.5 \mathrm{~h}$ & $\begin{array}{l}\text { MEISR + ICF-CY Profile } \\
+ \text { Functional Goals }\end{array}$ & Group work \\
\hline $5-$ & $4 \mathrm{~h}$ & $\begin{array}{l}\text { Functional Goals + other } \\
\text { RBEI Components }\end{array}$ & Presentation and discussion \\
\hline Field work $(3$ months $)$ & $\begin{array}{l}\text { Ecomap + RBI + } \\
\text { Functional Goals }\end{array}$ & $\begin{array}{l}\text { Follow up questions (E-learning } \\
\text { platform) }\end{array}$ \\
\hline $6-$ & Feedback & RBI + Functional Goals & Written feedback \\
\hline
\end{tabular}

Figure 1. Pre and Post Global Mean Quality by GFS III Item

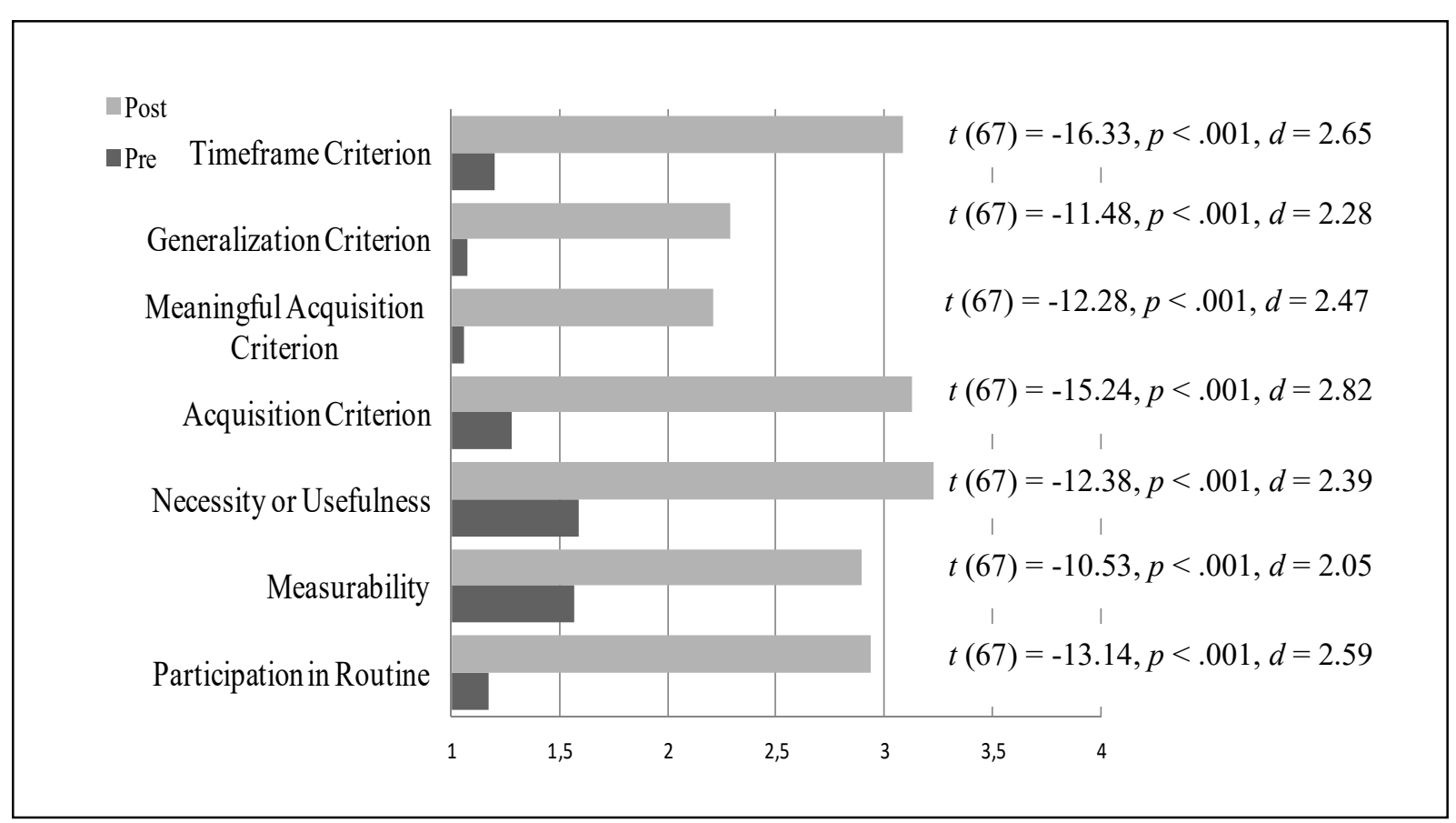

